\title{
WORKSHOP PEMBUATAN EXTRAK JAHE MERAH UNTUK MENINGKATKAN UMKM KARANG TARUNA KECAMATAN SETU, KOTA TANGERANG SELATAN, PROVINSI BANTEN
}

\author{
Niera Feblidiyanti, Rizky Aina As Syahadat, Achmad Chaerul Muslim \\ Dosen Fakultas Teknik Program Studi Teknik Industri \\ Universitas Pamulang \\ Dosen02275@unpam.ac.id
}

\begin{abstract}
The development and growth of UMKM (Micro, Small and Medium Enterprises) is one of the most important driving forces for economic development and growth in many countries, including Indonesia. This PKM activity was carried out by Karang Taruna, Setu District, South Tangerang City, Banten Province. The purpose of this community service activity is to help the people of Setu Subdistrict in a workshop for making red ginger extract to improve UMKM of the Youth Organization in Setu District, South Tangerang City, Banten Province, to help youth creativity in making red ginger extract products, and to help foster sustainability. The method of implementation is by conducting socialization, teaching, application and evaluation. The results of the PKM participants' understanding of the material provided were 10 people very understanding, 17 people understood, 8 people lacked understanding, and 5 did not understand.
\end{abstract}

\section{Keywords: Product Development, UMKM}

\begin{abstract}
Abstrak
Pembangunan dan Pertumbuhan UMKM (Usaha Mikro Kecil dan Menengah) merupakan salah satu motor penggerak yang sangat penting bagi pembangunan dan pertumbuhan ekonomi di banyak negara, tidak terkecuali Indonesia. Kegiatan PKM ini dilakukan Karang Taruna Kecamatan Setu, Kota Tangerang Selatan, Provinsi Banten. Tujuan kegiatan pengabdian kepada masyarakat ini adalah Membantu masyarakat Kecamatan setu dalam workshop pembuatan extrak jahe merah untuk meningkatkan UMKM Karang Taruna Kecamatan Setu, Kota Tangerang Selatan, Provinsi Banten, membantu kreativitas karang taruna dalam membuat produk extrak jahe merah, dan membantu membina berkelanjutan. Metode pelaksanaan yaitu dengan melakukan sosialisasi, pengajaran, aplikasi dan evaluasi. Hasil pemahaman dari peserta PKM mengenai materi yang diberikan adalah Sangat Paham 10 orang, Paham 17 orang, Kurang Paham 8 orang, dan tidak paham 5 orang.
\end{abstract}

Kata Kunci : Pembuatan Produk, UMKM 


\section{A. PENDAHULUAN}

Saat ini banyak makanan dan minuman yang ditawarkan sebagai produk suplemen yang dapat meningkatkan kesehatan tubuh jika dikonsumsi. Minuman kesehatan merupakan minuman yang mengandung unsur-unsur zat gizi atau non gizi dan jika dikonsumsi dapat memberikan pengaruh positif terhadap kesehatan tubuh. Minuman kesehatan sebagai salah satu produk yang sudah dikenal masyarakat, banyak dijumpai di pasaran dengan berbagai merek dan bentuk, seperti dalam bentuk cair, serbuk instan atau tablet. Kecenderungan masyarakat saat ini adalah lebih suka menggunakan produk yang kemasan dan penyajiannya lebih praktis dan cepat, karena tidak perlu membutuhkan banyak waktu dalam mempersiapkannya. Salah satu contoh minuman kesehatan yang dapat dijumpai adalah minuman instan ekstrak jahe. Jahe instan merupakan produk pangan yang berbentuk serbuk, terbuat dari ekstrak jahe yang ditambah gula atau rempah-rempah lain. Minuman instan ekstrak jahe dimanfaatkan untuk menciptakan produk yang praktis dan efisien, sehingga diharapkan diperoleh manfaat bagi kesehatan.

Wilayah Indonesia merupakan salah satu wilayah dengan iklim tropis dan subtropis, sehingga penyebaran tanaman jahe dapat tumbuh dengan baik. Jahe (Zingiber officinale rosc) merupakan salah satu jenis tanaman yang termasuk kedalam suku Zingiberaceae. Jahe (Zingiber officinale Rosc.) merupakan tanaman herba semusim yang dapat membentuk rimpang Sebutan tanaman ini bermacam-macam tergantung daerahnya, seperti halia (Aceh), lihai (Nias), sipadeh (Minang), jae (Jawa), lia (Flores), dan lali (Irian).

Jahe dibedakan menjadi 3 jenis berdasarkan ukuran, bentuk dan warna rimpangnya. Ketiga jenis itu adalah jahe putih atau kuning besar (jahe gajah atau badak) ukuran rimpangnya lebih besar dan gemuk jika dibandingkan jenis jahe lainnya. Jika diiris rimpang berwarna putih kekuningan, jahe putih atau kuning kecil (jahe emprit) struktur rimpang kecilkecil dan berlapis. Daging rimpang berwarna putih kekuningan, dan jahe merah atau jahe sunti. Struktur rimpang jahe merah, kecil berlapis-lapis dan daging rimpangnya berwarna kuning kemerahan, ukuran lebih kecil dari jahe kecil. Memiliki serat yang kasar. Jahe emprit dan jahe sunti mengandung minyak atsiri sebanyak $1,5-3,8 \%$ dari berat keringnya. Cocok untuk ramuan obatobatan atau untuk diekstrak oleoresin dan minyak atsirinya. Telah identifkasi kandungan senyawa kimia dari Jahe merah (Zingiber ofcinale Roscoe), yaitu gingerol, shogaol dan zingerone diketahui mempunyai efek farmakologi seperti antioksidan, antiin?ammasi, analgesic dan antikarsinogenik. Beberapa komponen bioaktif utama dalam jahe merah adalah : 4diarilheptanoid, shogaol, gingerol, dan gingeron memiliki aktivitas antioksidan di atas vitamin E (Ravindran, 2005).

Setu adalah kecamatan yang terletak di Tangerang Selatan, Provinsi Banten. Kecamatan setu merupakan salah satu wilayah yang merupakan dataran rendah dan memiliki topografi yang relatif datar dengan kemiringan tanah rata-rata $0-3 \%$ dan ketinggian wilayah antara $0-25 \mathrm{~m}$ dpl. Dilihat dari sebaran jenis tanahnya, kecamatan pada umumnya berupa asosiasi latosol merah dan latosol coklat kemerahan yang secara umum cocok untuk pertanian/perkebunan. Jahe merah dapat menurunkan intensitas nyeri karena kandungan oleoresin yang dimilikinya. Setyawan\& Tasminatun (2013) menjelaskan bahwa krim ekstrak Z. officinale dengan konsentrasi $10 \%$ dan $20 \%$ dapat menurunkan intensitas nyeri pada lansia. Secara in vitro, ekstrak Z. officinale dapat menghambat pembentukan komponen inflamasi, serta pemberian serbuk jahe pada penderita rematik dan musculoskeletal dilaporkan menurunkan intensitas nyeri juga pembengkakan. Selain itu, menurut Astuti (2011), terdapat penurunan nyeri otot secara bermakna $(p=0,008)$ pada atlet sepak takraw yang diberikan ekstrak jahe merah. 
Jahe merah ini memiliki permukaan kulit berwarna merah yang tentunya tidak sulit untuk dibedakan dengan jahe jenis lainnya. Adapun beberapa kegunaan dari jahe merah selain dari bumbu dapur ialah meredakan gejala batuk dan sakit tenggorokan, mampu mengurangi, kadar kolesterol dalam tubuh, meringankan sakit kepala, mengatasi rematik , melancarkan pencernaan, mengurangi risiko terkena radang usus, membantu meningkatkan sistem imun tubuh, meredakan dan mengobati penyakit asma atau sesak napas.

Berdasarkan latar belakang tersebut, kami dari Tim Program Pengabdian Masyarakat (PKM) Universitas Pamulang (UNPAM) yang berjumlah 3 dosen terpanggil untuk ikut serta membantu memecahkan persoalan yang dihadapi oleh masyarakat Kecamatan Setu dan ingin mengajak masyarakat Kecamatan Setu untuk workshop dalam pembuatan extrak jahe merah dengan judul PKM: "Workshop pembuatan extrak jahe merah untuk meningkatkan UMKM Karang Taruna Kecamatan Setu, Kota Tangerang Selatan, Provinsi Banten".

\section{B. METODE PELAKSANAAN}

Hal pertama yang dilakukan adalah perencanaan dimana tahap ini dilakukan survey sebagai langkah awal dalam melakukan Pengabdian Kepada Masyarakat. Melihat kondisi lingkungan dan masyarakat Kecamatan Setu, termasuk melakukan pengamatan permasalahan-permasalahan yang ada dan melihat kebutuhan penyuluhan yang diperlukan. Dari hasil pengamatan di lingkungan sekitar didapatkan bahwa masyarakat dalam kewirausahaan. Dari sana ditemukan bahwa masyarakat belum mengetahui Cara mengekstrak jahe merah yang mana bisa memiliki nilai ekonomis yang tiggi dan bisa meningkatkan taraf hidup anggota UMKM karang taruna dan masyarakat sekitar.

Langkah selanjutnya melakukan planning adalah menentukan tempat sosialisasi, membuat jadwal serta merinci peralata apa sajakah yang diperlukan. Langkah ketiga adalah pelaksanaan dilakukan dengan empat tahap adalah sebagai berikut:

1. Tahap sosialisasi

Pada tahap ini, team PKM melakukan sosialisasi di balai desa tentang cara mengekstrak jahe merah menjadi produk jadi yang memiliki nilai ekonomis yang lebih tinggi dari pada bahan mentah berupa jahe merah tersebut yang biasa digunakan sebagai bahan baku untuk pembuatan makanan dan untuk bahan minuman tradisional..Hal itu dapat menjadi peluang usaha sehingga menghasilkan peningkatan finansial ekonomi.

2. Tahap pengajaran

Pada tahap ini adalah mengajarkan secara teori bagaimana cara membuat ekstrak jahe merah, serta meberikan penngarahan mengenai usia jahe merah yang bagus untuk menjadi bahan baku produk skstrak jahe merah

3. Tahap aplikasi

Pada tahap tahap ini langsung melakukan Praktik simulasi pembuatan estrak jahe merah

4. Tahap evaluasi

Pada tahap ini adalah memberikan solusi terhadap permasalahan yang ada berkaitan dengan ekstrak jahe merah seperti kendala-kendala apa saja yang mungkin terjadi saat proses produksi, serta bagaimana cara menentukan produk yang dihasilkna memiliki kualitas yang bagus atau kurang bagus dan lain sebagainya.

Masalah umum yang akan dipecahkan dalam kegiatan ini, pertama adalah bagaimana meningkatkan mutu produk masyarakat di kecamatan Setu. Di mana dalam produksi ekstrak jahe merah diperlukan SOP (Standart Operational Procedure) untuk mengurangi kegagalan secara tepat, cepat dan cermat pada saat proses produksi. Kegiatan pelatihan dirancang 
sedemikian rupa dan disesuaikan dengan tingkat pemahaman serta karakteristik peserta pelatihan dalam hal ini adalah masyarakat cakupan wilayah Kecamatan Setu. Dimana juga menggunakan dengan bahasa yang mudah dipahami oleh peserta dan Pendidikan orang dewasa (POD). Pelatihan dilakukan dengan cara menstimulasi orang dewasa agar mampu melakukan proses ekstrak jahe merah.

Pelaksanaan kegiatan pengabdian di Kecamata Setu, Kota Tangerang Selatan melalui tahapan sebagai berikut:

1. Pendampingan pembelajaran konsep-konsep yang relevan tentang peningkatan kualitas mutu ekstrak jahe merah dan SOP (Standart Operational Procedure) pengelolaan jahe merah menjadi ekstrak jahe merah. Kegiatan ini diikuti oleh masyarakat khusunya para pedagang atau pelaku usaha di kecamatan Setu. Instruktur akan diberikan oleh dosen yang ahli di bidangnya dan didampingi oleh mahasiswa peserta PKM yang telah dilatih untuk materi tersebut. Metode yang digunakaan adalah pelatihan dan diskusi, dimana memberikan waktu untuk tanya jawab tentang materi yang diberikan.

2. Melakukan simulasi langsung bagaimana mengendalikan kualitas produk ekstrak jahe merah. Metode ceramah digunakan untuk penyampaian secara umum. Materi disampaikan dengan metode ini karena untuk tahapan pengenalan materi substantif secara keseluruhan dan memperoleh informasi secara umum dari peserta atau khayalak dalam hal ini pelaku usaha UMKM karang taruna yang berada di Kecamatan Setu. Selain menggunakan metode ceramah juga menggunakan metode demonstrasi dan latihan oleh mahasiswa. Demontrasi yang dimaksud pada metode ini adalah mempraktekkan dan memberikan pelatihan dalam membuat ekstrak jahe merah.

3. Pendampingan pelatihan dan pencontohan pengembangan usaha yang baik dari peningkatan mutu produk, sehingga dapat meningkatkan pendapatan masyarakat daerah Kecamatan Setu.

\section{HASIL DAN PEMBAHASAN}

\section{Metode Ekstraksi Mekanis Jahe}

Ekstraksi yaitu proses pemisahan suatu zat berdasarkan perbedaan kelarutannya terhadap dua cairan tidak saling larut yang berbeda. Biasanya air dan yang lainnya (pelarut organik). Metode ekstraksi mekanis yaitu metode dengan menggunakan alat yang bertujuan untuk menghancurkkan bahan dengan menggunakan pelarut sehingga didapatkan sari. Pemisahan dengan menggunakan sistem padat-cair dengan tujuan mendapatkan cairan jernih (bebas zat padat) yaitu cairan dimana tidak ada lagi zat-zat padat seperti serat didalamnya. Pemisahan sistem padat-cair dapat dilakukan dengan tiga cara yaitu pengendapan (sedimentasi), penyaringan (filtrasi) dan pemutara (sentrifusi). Pemisahan sistem padat cair dilakukan dengan penyaringan (filtrasi) dengan tujuan pemisahan cairan dari padatan. Penyaringan adalah pemisahan bahan padat dari cair dicapai dengan mengalirkan campuran penembus pori-pori yang cukup halus untuk menahan bahan padat. Ekstraksi dilakukan dengan penambahan air dalam jumlah tertentu untuk memperoleh sari jahe yang memiliki warna, aroma, serta cita rasa yang khas. Setelah proses ekstraksi berlangsung, biasanya akan terdapat endapan pada minuman sari jahe yang berasal dari komponen jahe yang tidak larut air. Rasio bahan: air pada proses ekstraksi dapat menentukan total senyawa kimia yang larut serta berpengaruh terhadap kenampakan dan cita rasa (Khoiriyah R.A, 2008). Semakin tinggi rasio air, maka semakin rendah partikel 
padatan terlarut. Salah satu faktor yang mempengaruhi kadar air dalam bahan pangan adalah ukuran partikel padatan (Lisna dkk, 2014).

\section{Hasil Kegiatan Pengabdian Kepada Masyarakat}
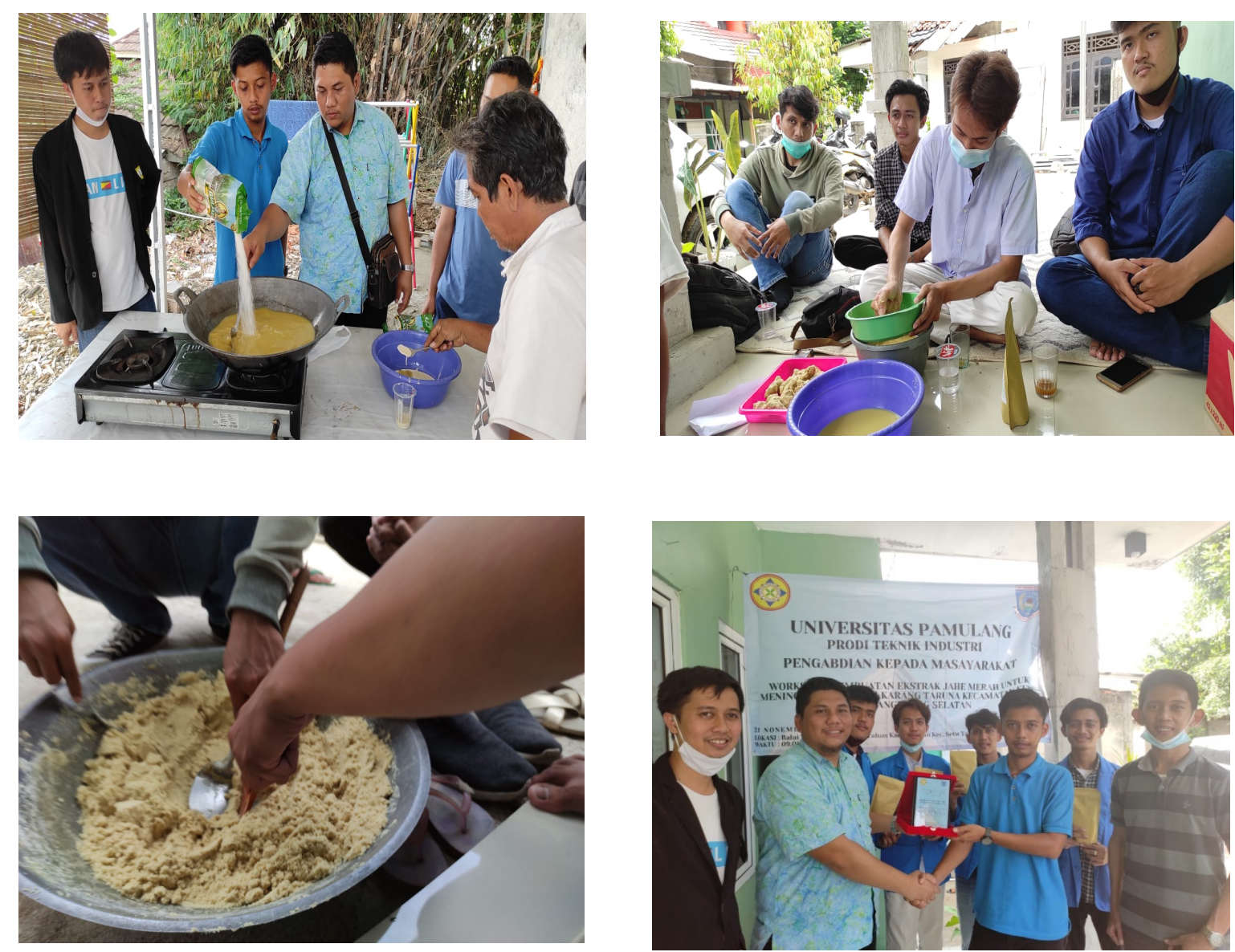

\section{Gambar 1. Pemberian Kenang-Kenangan ekstrak jahe merah oleh Team PKM}

Berdasarkan hasil survey yang dilakukan kepada masyarakat UMKM Karang Taruna Kecamatan Setu, Kota Tangerang Selatan, Provinsi Banten. setelah pelaksaan pengabdian masyarakat.

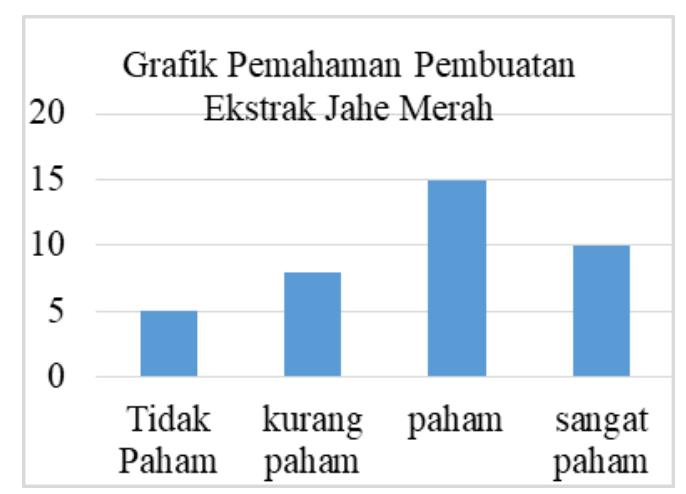

Gambar 2. Grafik Pemahaman Pembuatan Ekstrak Jahe Merah 


\section{KESIMPULAN DAN SARAN}

\section{Kesimpulan}

Berdasarkan hasil pelaksanaan kegiatan pengabdian kepada masyarakat oleh Lembaga Penelitian dan Pengabdian Masyarakat (LPPM) dan Dosen Program Studi Teknik Industri Universitas Pamulang adalah sebagai berikut:

1. Cara membantu masyarakat Kecamatan Setu, Kota Tangerang Selatan, Provinsi Banten untuk mengembangkan UMKM ekstrak jahe merah dengan memberikan materi dan praktek mengenai cara pembuatan ekstrak jahe merah.

2. Membantu menciptakan kreativitas masyarakat Kecamatan Setu, Kota Tangerang Selatan, Provinsi Banten dalam membuat suatu produk yaitu dengan melihat hasil kuesioner responden yang sangat paham 10 orang, paham 17 orang, kurang paham 8 orang, dan tidak paham 5 orang, artinya para responden bisa membuat produk ekstrak jahe merah dan bias dikembangkan sebagai produk UMKM.

3. Melakukan pembinaan berkelanjutan dengan cara melihat kuesioner dari pembuatan ekstrak jahe merah

\section{Saran}

Berdasarkan hasil kesimpulan didapatkan untuk menumbuhkan kreativitas masyarakat dalam membuat produk perlu didukung dari aparatur desa, mengenai fasilitas, peralatan bahkan dana operasionalnya:

\section{DAFTAR PUSTAKA}

Buckle, K.A., R.A. Edwards, G.H. Fleet and M. Wotton. 1985. Ilmu Pangan. Penerjemah Hari Purnomo dan Adiono. UI-Press, Jakarta.

Khoiriyah, R. A. 2008. Karakteristik Minuman Jeli Anggur Lokal (Vitis vinifera) (Kajian Rasio Bahan : Air dan Konsentrasi Karagenan Terhadap Sifat Fisik, Kimia dan Organoleptik). Skripsi. Fakultas Teknologi Pertanian. Universitas Brawijaya. Malang.

Lisna, M. Yuwono, S.S. Ningtyas, D.W. 2014. Pengaruh Pengecilan Ukuran Jahe dan Rasio Air Terhadap Sifat Fisik Kima dan Organoleptik Pada Pembuatan Sari Jahe.Jurusan Teknologi Hasil Pertanian, FTP Universitas Brawijaya, Malang. Jurnal Pangan dan Agroindustri 2(4):148:158.

Paimin, B.P. dan Murhananto. 1991. Budidaya, Pengolahan dan Perdagangan Jahe. Penebar Swadaya. Jakarta.

Soekarto, T.S. 1985. Penilaian Organoleptik Untuk Industri Pangan dan Pertanian. Bhratara, Jakarta.

Susanto, T dan Saneto, B. 1994. Teknologi Pengolahan Hasil Pertanian. PT. Bina Ilmu. Surabaya.

Undriyani, K. 1987. Pengaruh Bubuk Jahe (Zingiber of7icinale Rosc.) terhadap Aktivitas Pertumbuhan Beberapa Mikroba Penyebab Kerusakan Pangan. Makalah Khusus. Fateta-IPB. Bogor 